\title{
Smoke Hazard Assessment on Offshore Oil and Gas Installations
}

\author{
BALDEV S. KANDOLA \\ AEA Consultancy Services \\ Thomson House, Risley, Warrington WA3 6AT \\ United Kingdom
}

\begin{abstract}
In an emergency situation on a offshore production platform, a Temporary Safe Refuge (TSR) is required to provide life support for a set period until such time that a complete evacuation is carried out. Uncontrolled ingress of smoke resulting from external fires can cause visibility and toxic hazards to personnel inside the TSR. A proper design and location of a TSR with respect to potential fire hazards can minimize these effects. To carry out toxic hazard assessment, AEA Technology have developed a computer code SMILE. This code has been successfully used on numerous existing North Sea installations. The code calculates the build up of combustion products inside a TSR, from which the levels of visibility and toxicity are estimated. This paper briefly discusses the theoretical background to the smoke ingress problem and the application of the SMILE code.
\end{abstract}

KEYWORDS: smoke, ingress, modelling, wind, fire, toxicity, visibility, offshore, stack, hazard

\section{NOTATION}

$\begin{array}{ll}\text { A } & \text { - area of opening } \\ \text { B } & \text { - a constant (equation 10) } \\ \mathrm{C}_{\mathrm{d}} & \text { - discharge coefficient } \\ \mathrm{C}_{\mathrm{s}} & \text { - smoke aerosol concentration } \\ \mathrm{C}_{\mathrm{p}} & \text { - specific heat } \\ \mathrm{D} & \text { - fire diameter, smoke optical density } \\ \mathrm{F} & \text { - toxic dose over time } \mathrm{t}_{\mathrm{d}} \\ \mathrm{g} & \text { - acceleration due to gravity } \\ \mathrm{H}_{\mathrm{c}} & \text { - heat of combustion of fuel } \\ \mathrm{h} & \text { - neutral pressure plane height } \\ \mathrm{I} & \text { - light intensity in smoke } \\ \mathrm{I}_{\mathrm{o}} & \text { - light intensity without smoke } \\ \mathrm{K} & \text { - extinction coefficient } \\ \mathrm{K}_{\mathrm{m}} & \text { - specific extinction coefficient } \\ \mathrm{L}^{\circ} & \text { - optical path length } \\ \dot{M}_{\mathrm{g}} & \text { - smoke mass production rate } \\ \dot{\mathrm{m}}_{\mathrm{a}} & \text { - rate of air entrainment } \\ \dot{\mathrm{m}}_{\mathrm{p}} & \text { - rate of production of combustion }\end{array}$
$\mathbf{r}_{\mathbf{z}}$ - plume radius
$\mathrm{T}$ - plume centreline temperature
$\mathrm{T}_{0}$ - ambient air temperature
$\mathrm{T}_{\mathrm{i}}$ - enclusure temperature
$\mathrm{t}_{\mathrm{e}}$ - time to steady state conditions
$\mathrm{V}_{\mathrm{c}}$ - enclosure volume
$\dot{\mathrm{V}}_{\mathrm{g}}$ - volume rate of flow of gases
$\dot{\mathrm{V}}_{\mathrm{T}}^{\mathrm{g}}$ volume rate of flow of smoke
$\mathrm{W}_{\mathrm{s}}$ - mass of smoke aerosol
$\dot{\mathrm{W}}_{\mathrm{g}}$ - mass rate of flow of smoke into enclosure
$\dot{w}_{j}$ - mass rate of flow of compound $j$ into
enclosure
$\dot{\mathrm{w}}_{\mathrm{cp}}$ - mass rate of flow of combustion products
into enclosure
$\mathrm{Y}_{\mathrm{s}}$ - smoke yield (mass of smoke aerosol/mass
of fuel burned)
$Y_{j}$ - yield of component $j$
$z$ - height above fire source


products

$\dot{\mathrm{m}}_{\mathrm{l}} \quad$ - mass burning rate

$\mathrm{Q}_{\mathrm{c}} \quad$ - convective heat flux

\section{GREEK SYMBOLS}

$\Delta T$ plume centreline temperature above ambient

$\Delta p_{i j}$ pressure difference across flow path

$\rho_{o} \quad$ density of ambient air

$\rho_{s}$ density of smoke

$\eta_{c} \quad$ convective heat output fraction

\section{INTRODUCTION}

Following the Piper Alpha disaster inquiry, one of the recommendations of the Lord Cullen's report concerns the safety of the accommodation areas and the Temporary Safe Refuge (TSR). The report recommends that active and passive protection measures should be provided to "... prevent ingress of smoke and other contaminants into the accommodation and to maintain breathable air within $i t^{\prime \prime}$ [1]. It further emphasises that operators should carry out "... an assessment of the risk of ingress of smoke or gas into the accommodation...".

In an emergency situation involving fire or accidental release of gas the TSR is required to provide life support for a set period until such time that a complete evacuation can be carried out. Among other things TSR should be able to maintain breathable air by limiting the ingress of smoke and other combustion products resulting from external fires (Figure 1.1). In addition, it is required that smoke should not hinder, by way of reduced visibility, full and safe evacuation of the installation.

These objectives can only be met if the build up of toxicity and the visibility (i.e. smoke optical density) inside the accommodation building are kept well within the prescribed safe limits.

The flow of outside air (smoke laden or contaminated) into a leaky building is a complex phenomenon. It is determined not only by the leakage characteristics of the building envelope but most importantly by the driving forces arising from buoyancy, atmospheric wind and the air conditioning system (the HVAC). These factors are difficult to quantify accurately because of the uncertainties associated with their measurement. The leakage of a building (cracks around doors and windows) for example is subject to wide variations due to workmanship, daily usage and weathering. The turbulent and variable nature of wind and its interaction with the building structure further adds to these uncertainties. In addition the smoke production properties of a fire, its dispersion in the atmosphere are the other complicating factors making the task of assessment difficult.

However, this is not to say that the problem of smoke ingress is an intractable one. On the contrary, it is possible with the sound theoretical understanding of the phenomena involved, together with the tangible empirical evidence, to analyse and predict the "worst case" scenario. The aim of risk assessment is achieved if it gives us the ability to control or circumvent a catastrophic event.

This paper describes such a methodology for assessing the effects of smoke ingress from fires occurring outside of the accommodation building. By identifying the mechanisms of smoke movement and spread, the ingress rate is calculated from which the levels of visibility and 
smoke concentration are calculated within the accommodation building. These results are then used to assess the time to reach untenable conditions arising from toxicity, visibility or oxygen starvation (ie the breathability of air).

To carry out the smoke hazard assessment AEA Technology have developed a computer code SMILE which has been successfully used on numerous existing North Sea installations. This paper briefly discusses the theoretical background to the smoke ingress problem and the application and evolution of the SMILE code.

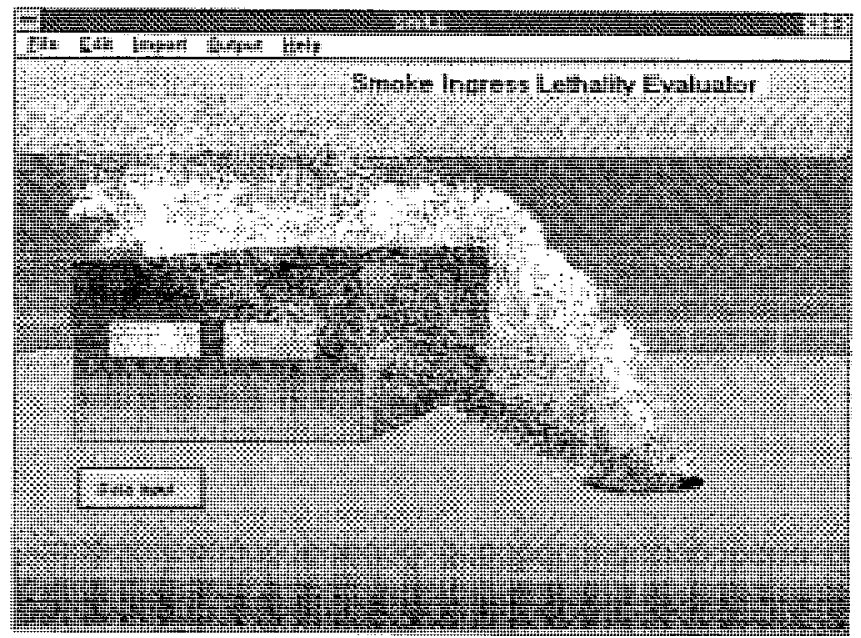

FIGURE 1.1 Temporary safe refuge (TSR) fire scenario

\section{SMOKE PRODUCTION FROM OIL POOL FIRES AND ITS PROPERTIES}

\subsection{Smoke Plume}

For a buoyant plume resulting from a fire smoke can be thought of as made up of entrained air and the products of combustion. From the plume theory $[2,3,4,5]$ the mass rate of production of smoke at an elevation, $z$, above the fire surface is given by:

$\dot{M}_{g}=0.071 Q_{c}^{1 / 3}\left(z-z_{0}\right)^{5 / 3} \cdot\left\{1+0.026 Q_{c}^{2 / 3}\left(z-z_{0}\right)^{-5 / 3}\right\}$

where $z_{0}=-1.02 D+0.083 Q^{2 / 5}$

and, $Q_{c}=\eta_{c} \dot{m}_{f} H_{c}$

The plume centreline temperature rise $(\Delta T)$ and radius are given by:

$$
\begin{aligned}
& \Delta T=9.1\left\{\frac{T_{0}}{\left(g c_{p}^{2} \rho_{0}^{2}\right)}\right\}^{1 / 3} Q_{c}^{2 / 3}\left(z-z_{0}\right)^{-5 / 3} \\
& r_{z}=0.12\left(\frac{T}{T_{0}}\right)^{1 / 2}\left(z-z_{0}\right)
\end{aligned}
$$




\subsection{Smoke Optical Density and Visibility}

Generally, smoke resulting from fires is associated with reduced visibility due to the light scattering and absorption properties of the solid particle components of smoke (soot particles). The optical density of smoke is a measure of the light obscuration properties of solid particles. The increase in the number distribution of particles in a given volume result in the increased optical density and reduced visibility. The optical density, D, is defined as [6]:

$$
I / I_{o}=10^{-D L}
$$

When equation (6) is expressed in terms of natural logarithm, $e$

$$
I / I_{o}=e^{-K L}
$$

The quantity $\mathrm{K}$ is the extinction coefficient.

In general visibility is expressed in terms of a distance, $S$, at which an object is clearly visible to an observer under the room lighting conditions. Visibility depends on many factors such as the optical density of smoke (or extinction coefficient), the illumination in the room and whether the object is light emitting or light reflecting.

The relationship between visibility and extinction coefficient is expressed as:

$$
K . S=B
$$

Experiments show that for light emitting signs, $B=8$ and for light reflecting signs, $B=3$ [4].

The extinction coefficient per unit path length, $\mathrm{K}$, is usually expressed in terms of smoke aerosol concentration, $\mathrm{C}_{s}$.

$$
K=K_{m} C_{s}
$$

where $C_{s}$ is in $g / \mathrm{m}^{3}$ and $K_{m}$ is the specific extinction coefficient of smoke $\left(\mathrm{m}^{2} / \mathrm{g}\right.$ ). For an enclosure, the concentration, $\mathrm{C}_{\mathrm{s}}$, can be expressed as:

$C_{s}=W_{s} / V_{c}=Y_{s} \dot{m}_{f} \dot{V}_{T}$

where $\dot{m}_{f}$ is the fuel mass burning rate $(\mathrm{g} / \mathrm{s})$ and $\mathrm{Y}_{\mathrm{s}}$ smoke yield

For a developing fire, the average aerosol (i.e soot) concentration can be expressed as:

$C_{s}=Y_{s} \int_{0}^{t} \dot{m}_{f}(t) d t / \int_{0}^{t} \dot{V}_{T}(t) d t$

\subsection{Smoke Toxicity}

The effects of toxic products of combustion such as carbon monoxide (CO) and carbon dioxide $\left(\mathrm{CO}_{2}\right)$ are investigated by calculating the build up of concentration of these products in a given enclosure. The results are then compared with the laboratory experiments on animals [6].

In assessing the physiological effects of hazards of smoke/gas inhalation, a concept of dose is defined which gives the accumulated body burden of inhaled toxicants. By definition, dose is a function of smoke concentration and exposure time. 
The concentrations of gas toxicants are usually expressed as parts per million (ppm) by volume. For a time varying concentration the dose is the integrated area under a concentration vs time curve.

Toxic exposure tests on animals suggest that smoke from most common materials are characterised by lethal doses in the range of $300 \mathrm{mg}$-min/liter to $1500 \mathrm{mg}$-min/liter with the average being about $900 \mathrm{mg}$-min/liter. Incapacitating dose would be expected to lie at perhaps $300 \mathrm{mg}$-min/liter [6].

Carbon dioxide $\left(\mathrm{CO}_{2}\right)$ is produced in most fires. Inhalation of carbon dioxide stimulates respiration which in turn increases intake of oxygen and other toxic gases produced by the fire. Experiments show [8] that a 30 minute exposure to $50000 \mathrm{ppm}(5 \%)$ produces signs of intoxication. Threshold limit for carbon dioxide is around $5000 \mathrm{ppm}$.

Inhalation of $\mathrm{CO}$ gas causes asphyxiation by combining with haemoglobin in a reversible reaction to form carboxyhaemoglobin. A daily highest concentration to which man may be exposed without adverse effect is about $50 \mathrm{ppm}$.

\subsubsection{Calculation of Smoke Toxicity}

When a material burns in the presence of oxygen various chemical compounds are generated in addition to heat and aerosols. For example in the burning of a carbon based material in the air the carbon atoms are converted to $\mathrm{CO}, \mathrm{CO}_{2}$, smoke and other carbon containing compounds.

The yield of a compound, $\mathrm{j}$, is defined as:

$$
Y_{j}=\dot{m}_{j} / \dot{m}_{f}
$$

From the burning rate and yield the mass rate of production of each compound can be calculated.

For a fire plume if the mass rate of production of smoke, $\dot{M}_{8}(z)$, is known then the ratio of mass of compound $\mathrm{j}$ to the mass of smoke at an elevation $\mathrm{z}$ in the plume is:

$$
r_{j}=\dot{m}_{j}(z) / \dot{M}_{g}(z)
$$

If the mass rate of flow of smoke into an enclosure, $\dot{W}_{g}$, is known then the mass rate of flow of compound $\mathrm{j}$ into the enclosure is given by:

$$
\dot{w}_{j}=\dot{W}_{8}, r_{j}\left(z_{1}\right)
$$

If the total number of compounds produced by the fire is $\mathrm{N}_{c}$, the mass rate of flow of combustion products into the enclosure, $\dot{w}_{c p}$, can be written as:

$\dot{w}_{c p}=\sum_{j=1}^{N_{c}} \dot{w}_{j}=\dot{W}_{8} \sum_{j=1}^{N_{c}} r_{j}\left(z_{1}\right)$

As smoke flows into the enclosure the concentration of combustion products increases until the steady state conditions are reached. In order to calculate the time to steady state conditions, it is assumed that the enclosure air is replaced by smoke at the inflow rate. Hence the time taken to reach steady state conditions is the time required to fill the volume of enclosure, $\mathrm{V}_{\mathrm{c}}$.

The volume rate of flow of smoke into the enclosure is given by:

$$
\dot{V}_{g}=\dot{W}_{g} / \rho_{s}
$$


Then the time required to reach steady state conditions is:

$$
t_{e}=V_{c} / \dot{V}_{8}
$$

The total mass of combustion products in the enclosure after time $t_{e}$ is:

$$
W_{e}=\dot{w}_{c p} \cdot t_{e}
$$

Then the concentration of combustion products in the enclosure is:

$$
C_{c}=W_{e} / V_{c}
$$

The toxic dose over an exposure time of $t_{d}$ is given by:

$F=C . t_{d}=\int_{0}^{t_{c}} \frac{\dot{W}_{c p} \cdot t}{V_{c}} d t+\int_{s_{e}}^{t_{d}} \frac{W_{c}}{V_{c}} d t$

integrating with initial conditions $\mathrm{F}=0, \mathrm{~W}_{\mathrm{e}}=0$ at $\mathrm{t}=0$ equation (20) becomes:

$F=\frac{\dot{w}_{c p}}{V_{c}} \cdot \frac{t_{e}^{2}}{2}+\frac{W_{e}}{V_{c}} \cdot\left(t_{d}-t_{e}\right)$

For a given threshold value for dose, $F$, the time to reach this level, $t_{d}$, can be calculated. From equation (21) it is clear that in order to calculate $t_{d}$ the mass rate of flow of combustion products into the building $\left(\dot{w}_{c p}\right)$ i.e the ingress rate must be known. This is calculated by examining the mechanisms of smoke movement.

If the pressure difference across an opening is known (Eg from stack effect or wind effect studies) the mass flow rate can be calculated using the following general relationship:

$\dot{m}_{(i, j)}=C_{d} A \sqrt{\left(2 \rho \Delta p_{i j}\right)}$

where $\dot{m}_{(i, j)}$ is the mass flow rate from zone $\mathrm{i}$ (Eg outside) to zone $\mathrm{j}$

CALCULATION OF SMOKE INGRESS RATE

In the offshore environments there are two main forces causing the flow of smoke into a given building (e.g. the accommodation block). They are: the stack effect and the atmospheric wind. Because of the size of these accommodation blocks (usually single storey high) the wind effects often dominate.

\subsection{Stack Effect}

The difference in temperature between the building interior and the outside results in the flow of air into and out of the building through leakage paths such as cracks around doors and windows. If the internal temperature is higher than that outside, air in the building has the tendency to rise due to its buoyancy and colder denser air outside enters the building to replace it. This phenomenon is generally known as the stack effect. The flows are reversed when the internal temperature is lower than that outside and the effect is conveniently refered to as the reverse stack effect.

At some height from the ground level a neutral pressure plane exists such that there is no flow across the openings at this height. 
The height of this neutral plane is determined by the leakage characteristics of the building. To maintain mass balance, the total inflow below the neutral plane must equal the total outflow above it. Thus the neutral plane tends to be close to large leaks.

If the position of the neutral pressure plane is known the pressure difference due to stack effect is given by $[8,9]$ :

$\Delta P_{s}=3408 h\left(\frac{1}{T_{o}}-\frac{1}{T_{i}}\right)$

Under certain situations the smoke movement within a building can be dominated by the stack effect and can cause smoke to be transported considerable distances from the seat of the fire.

For a small building, such as the offshore accommodation module, the stack effect may not be of importance. For example if the neutral plane is assumed to be located at the mid height of a $16 \mathrm{~m}$ high block with inside and outside temperatures of $20^{\circ} \mathrm{C}$ and $0^{\circ} \mathrm{C}$ the pressure difference due to stack effect, according to equation (23), is 7.0Pa.

\subsection{Wind Effects}

The atmospheric wind can have a marked influence on flows within a leaky building. In some cases it can override the stack effect, depending on the wind speed and the building leakage characteristics [10]. Wind induced pressures can either spread or clear smoke within a building depending on the location of fire relative to the wind direction.

The wind induced flows around buildings are very complex. They depend not only on the building shape and size but also on the surrounding terrain and wind speed and turbulence (Figure 3.2). Generally, however, positive wind induced pressures are generated on the upwind side of buildings while the other sides and the roof experience negative wind induced pressures. Accordingly, air flows into the building through leakages on the windward side and leaves through those on the other sides $[10,11]$.

In practise, because of the stochastic (i.e random) nature of wind speed and direction, the wind-induced pressure distribution inside a building structure can be time-varying and difficult to predict. In the absence of any theoretical model describing the time dependent variation of pressure, the assumption of steady-state conditions is generally made in the analysis of internal flows.

Normally, the offshore structures are exposed to very high wind speeds (typically $20 \mathrm{~m} / \mathrm{s}$ ). The wind induced pressure difference across the outside entrance door for an accommodation block could be as high as $200 \mathrm{~Pa}$. This is considerably higher than the contribution from the stack effect (7Pa, section 3.1). Under such conditions, for the analysis of "worst case scenarios" the stack effects contribution may justifiably be neglected to simplify the calculation procedure. 


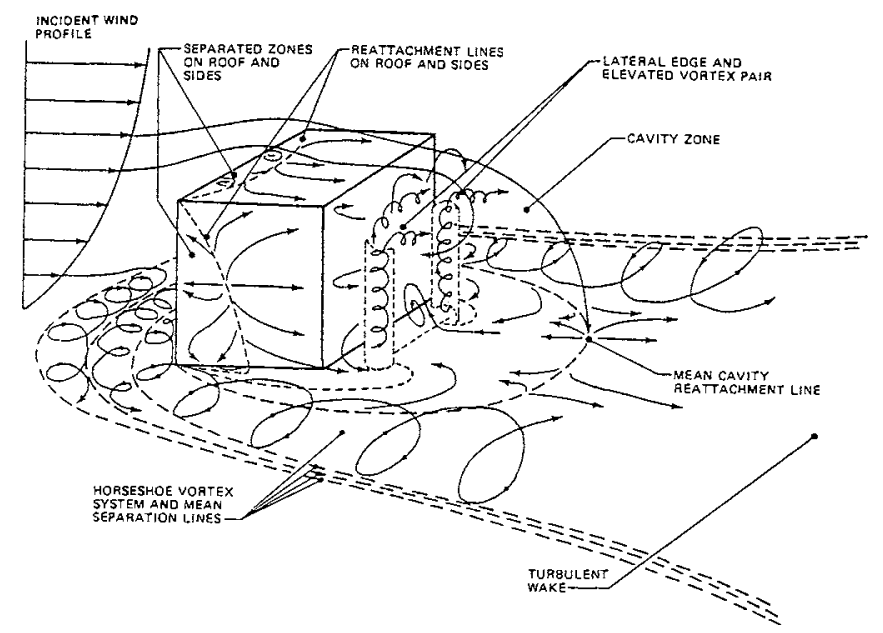

FIGURE 3.2 Wind induced flow over and near a building [Hosker]

4 TSR SMOKE INGRESS ANALYSIS - A WORKED EXAMPLE

In an enclosed volume the dominant effects of exposure to smoke from fires are: visual obscuration, toxic effects and asphyxiation due to the reduced oxygen concentration.

In a fire situation these effects generally occur simultaneously, contributing to physical incapacitation, loss of motor coordination (hindering escape), disorientation and restricted vision. The resulting delay in escape may lead to unconciousness or subsequent death from further inhalation of toxic gases.

Although, the heat radiation effects are confined to the immediate vicinity of a fire, the effects of smoke can be manifest even at large distances from the fire. In offshore environments where the evacuation is only possible by boat or some other sea craft, the evacuees are therefore required to wait, sometime for hours, inside the accommodation modules. Under these conditions the rate of smoke ingress and the subsequent build-up of smoke concentration are important.

The time to incapacitation and visibility are important for evacuation and escape from the effects of an external hydrocarbon fire. An assessment of these parameters can be carried out using the computer code SMILE (Smoke Ingress Lethality Evaluator).

Information required to assess smoke hazard with SMILE:

1. Location and size of fire, fire duration and burning rate

2. Type and amount of fuel

3. Wind speed and direction at the time of fire

4. Size of the accommodation building

5. Leakage characteristics of the building including vent openings

6. Ventilation system inlet and outlet (size and location), flow rate

8. Details of other aerodynamic obstructions in the vicinity of the building (e.g. blast walls, other modules etc.) 
For complicated fire scenarios the code is used in conjunction with the computational fluid dynamics code CFDS-FLOW3D.

CFDS-FLOW3D is a computational fluid dynamics code used widely for the calculation of industrial flows. Within AEA Technology, its use has also been made in the prediction of wind induced pressure distribution on buildings and structures. Figure 4.1 shows a comparison wind tunnel results with the CFDS-FLOW3D [Ref. 12] predictions, for wind angle normal to one of the walls. The predictions show a very good comparison with the measured results.

For a building under investigation the results from the CFDS-FLOW3D analysis are used as input into the SMILE package to calculate the ingress rate. The steps required for the smoke ingress analysis are summarised in Figure 4.2.

\subsection{Worked Example}

Consider a module of dimensions $30 \mathrm{mx} 15 \mathrm{mx} 5 \mathrm{~m}$, situated at a distance of $20 \mathrm{~m}$ from the centre of a crude oil pool fire, area $10 \mathrm{~m}^{2}$ (Figure 4.3). For the purposes of this calculation it is assumed that the smoke concentration at the near wall is the same as the smoke concentration at the plume centre-line at a height $20 \mathrm{~m}$ above the pool.

There are two doors of size $1 \mathrm{~m} \times 2 \mathrm{~m}$ located on opposite walls. The leakage area for each door is assumed to be $0.012 \mathrm{~m}^{2}$ with a wind speed of $10 \mathrm{~m} / \mathrm{s}$.

Results: The build up of smoke, carbon dioxide and carbon monoxide concentration as function of time are shown in Figure 4.4, Figure 4.5 and Figure 4.6 respectively. These results allow the dose values to be calculated for a given period of time (area under the curve). From a knowledge of the threshold value (e.g. from tests on animals) the time to escape can then be computed.

The calculated results for this scenario are summarised in Figure 4.7. They show that the time to lethal dose within the module is just under two hours (112 minutes). This means that if the evacuation is carried out within 112 minutes in occupants are unlikely to suffer any ill-effects. The visibility after one hour reduces to $5 \mathrm{~m}$ for light reflecting signs.

\section{ACKNOWLEDGEMENTS}

The Author wishes to thank Mr Hayden Pugh and Mr Nigel Ashton both of AEA Technology Consultancy Services for the assistance rendered in writing the SMILE code.

\section{REFERENCES}

1 The Hon Lord Cullen, The Public Inquiry into the Piper Alpha Disaster, Department of Energy, HMSO, London, 1991.

2 D. Evans, G. Mulholand, D. Gross, H. Baum, W. Walton, Burning, Smoke Production. and Smoke Dispersion from Oil Spill Combustion, NISTIR - 89/4091, October 1989.

3 Gunnar Heskestad, Engineering Relations for Fire Plumes, Fire Safety Journal, 7 (1984) 25-32.

4 George W. Mulholland, Smoke Production and Properties, The SFPE handbook of Fire Protection Engineering, NFPA, 1988.

5 D. D. Drysdale, Introduction to Fire Dynamics, John Wiley \& Sons, New York (1985). 

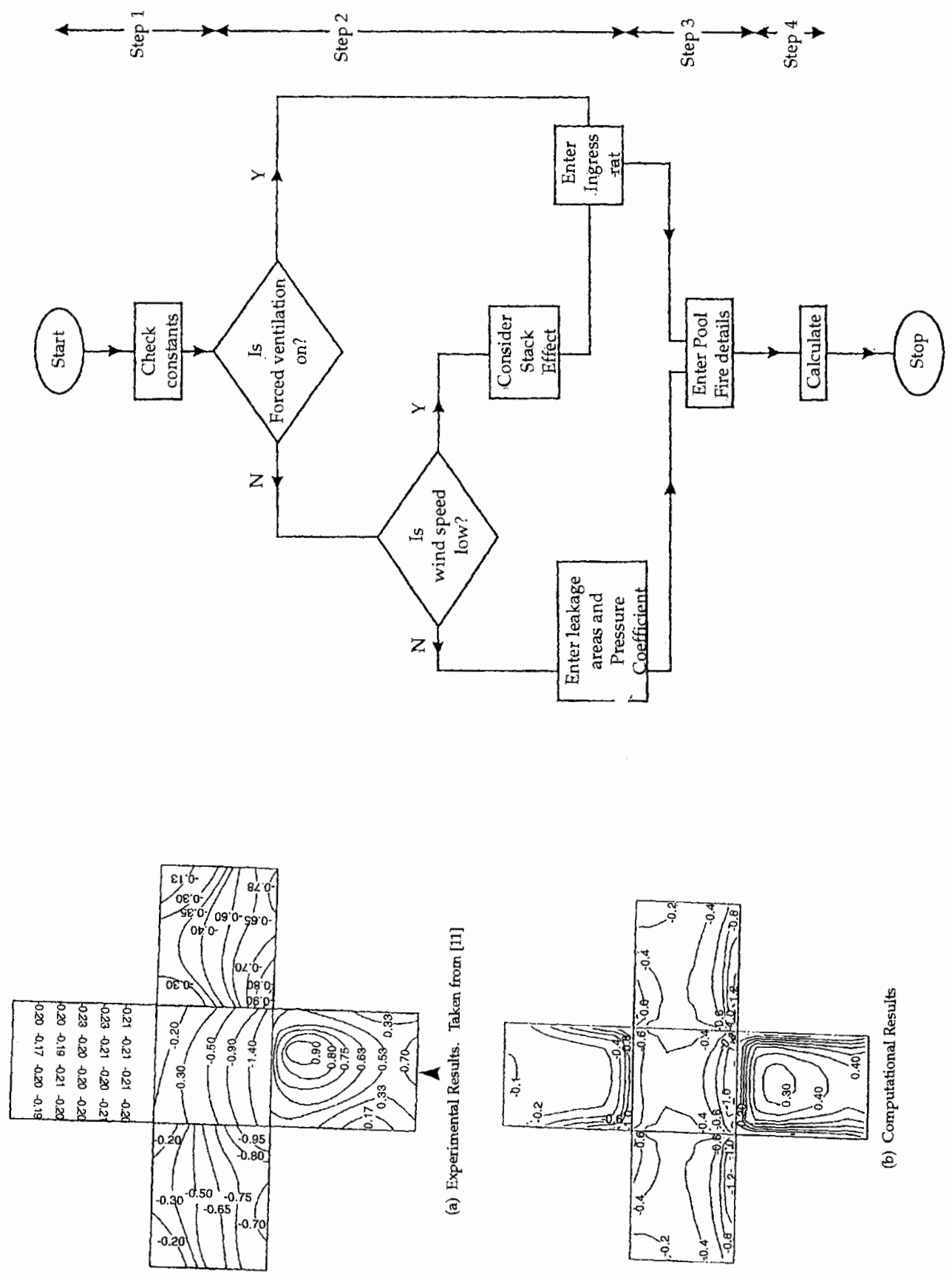

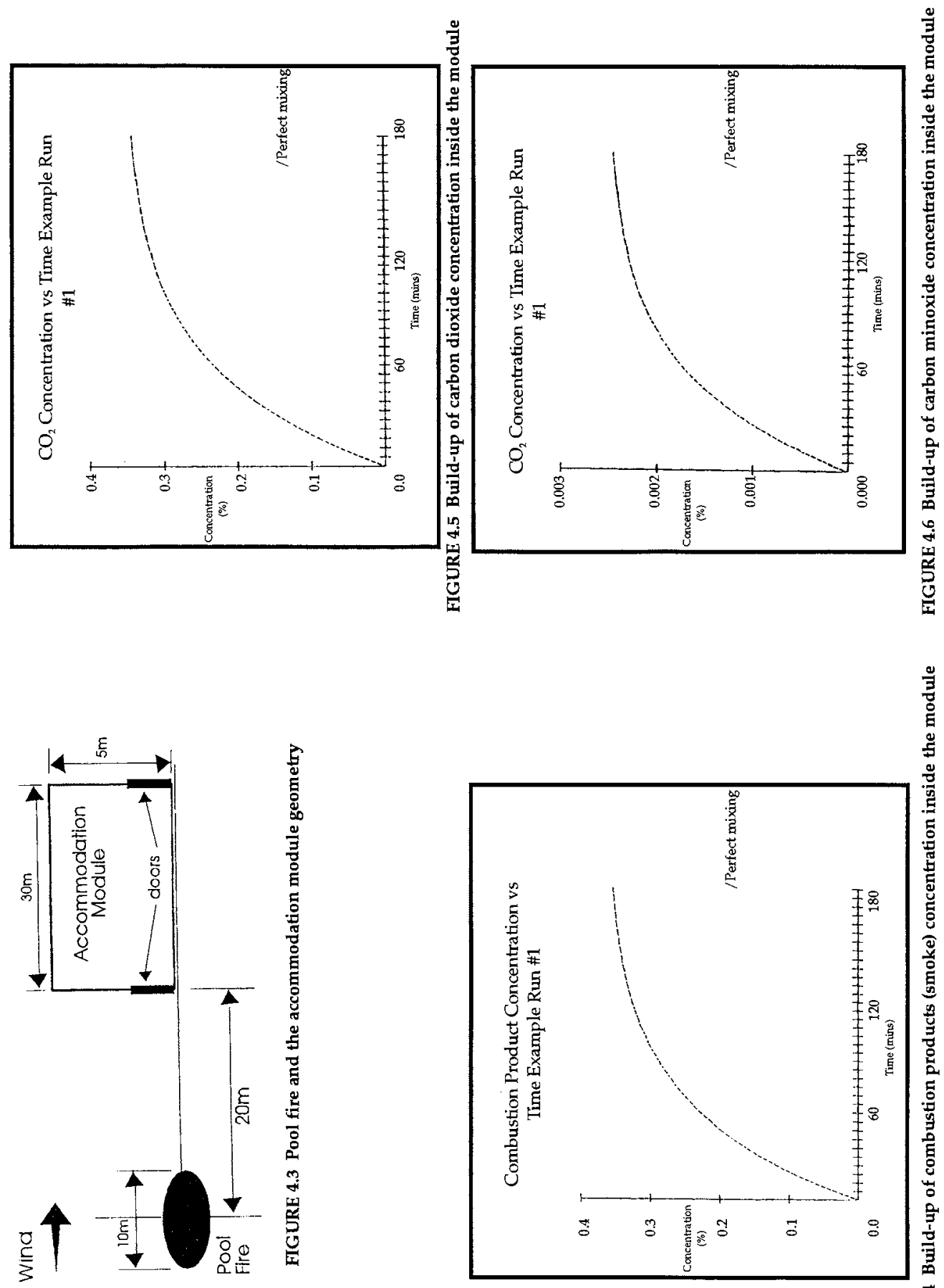

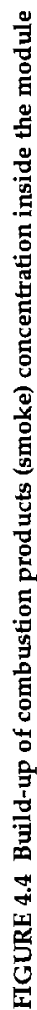


6 G. E. Hartzell (Ed.), Advances in Combustion Toxicology, Technomic Publishing Co. Inc., 1989.

7 E. E. Zukoski, Eluid Dynamic Aspects of Room Fires, Proceedings of the First International Symposium of Fire Safety Science, 1986.

8 John H. Klote, Considerations of Stack Effect in Building Fires, NISTIR 89-4035, January 1989.

9 B. S. Kandola, Effects of Atmospheric Wind on Flows through Natural Convection Roof Vents. Fire Technology May 1990.

10 B. S. Kandola and E. W. Marchant, Wind-induced Movement of Smoke within and around Buildings- A wind tunnel Investigation, 5th Int. Conf, on Wind Eng., Colorado, (1978).

11 R P Hosker, Empirical Estimation of Wake Cavity Behind Block-type Structures, Fourth Symp. on Turbulence, Diffusion, and Air Pollution, Reno, Nev., Jan 15-18, 1979, pp 603-609, American Met. Society, Boston, Mass.

12 CFDS, 'FLOW3D User Guide', CFDS, AEA Technology, Harwell Laboratory, 1992.

Smoke Ingress Lethality Evaluator

SMILE Version 1.0

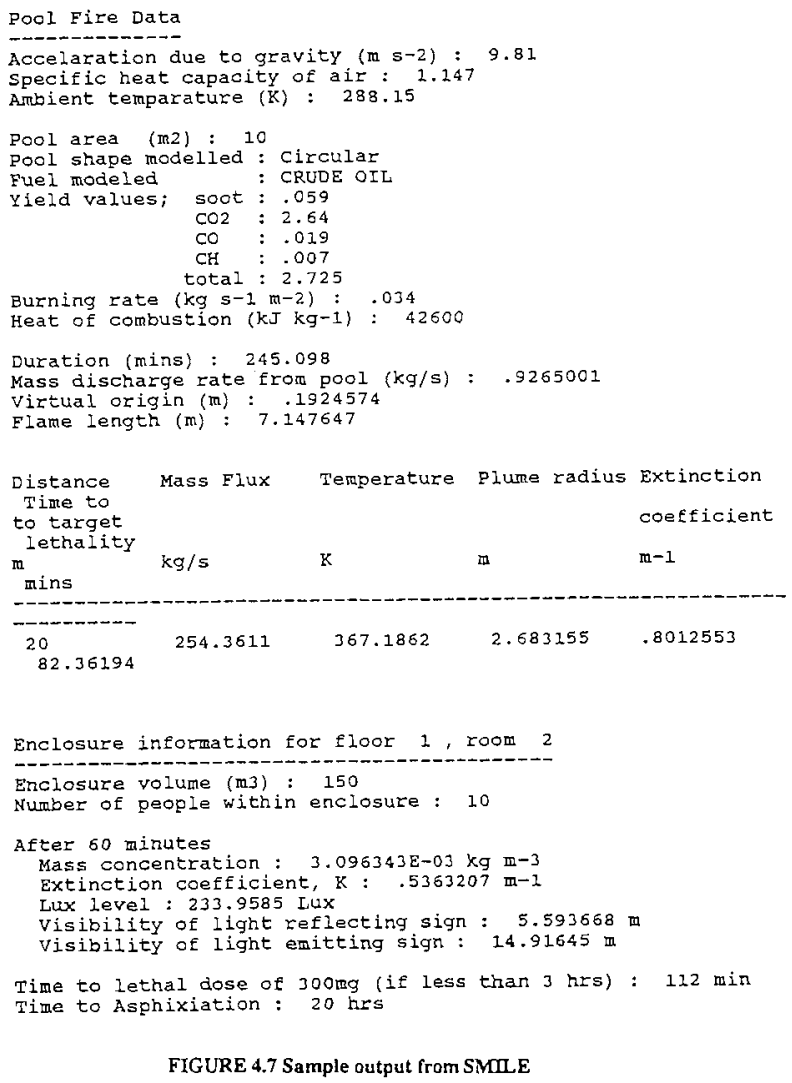

FIGURE 4.7 Sample output from SMULE 